\title{
Long QT syndrome, utility of bicameral pacemaker
}

\author{
Síndrome de QT largo, utilidad del marcapasos bicameral \\ Leonardo Rivera-Rodriguez* y Liliana López-Hernández \\ Departamento de Cardiología Pediátrica. Instituto Nacional de Cardiología "Ignacio Chávez," Ciudad de México, México
}

The use of implantable cardioverter defibrillator (ICD) in pediatric age represents a challenge, because of anatomic limitations, increased risk of lead fracture, $T$ wave oversensing and inappropriate therapies ${ }^{1}$. We present a case of a 4-year-old boy with no medical history of heart disease and no family history of sudden death, who was admitted to our institution with 1 month of recurrent syncope. He received treatment with lidocaine in other hospitals due to broad QRS complex tachycardia. The physical examination was unremarkable. The echocardiogram was normal. The electrocardiogram shows a long QTc of $510 \mathrm{~ms}$ and prolonged ST segment, suggesting long QT type III (LQT3) (Fig. 1).

During the $1^{\text {st }}$ day of admission, he presented a polymorphic ventricular tachycardia with a heart rate of 220 $\mathrm{bpm}$, preceded of premature ventricular contractions (Fig. 2).

He required electric cardioversión with $1 \mathrm{~J} / \mathrm{kg}$ and 2 $\mathrm{J} / \mathrm{kg}$ in three occasions, afterward treatment with intravenous magnesium and beta-blocker was started. Then, a endocardial dual-chamber pacemaker was implanted in the $3^{\text {rd }}$ day since admission without complications (Fig. 3). The patient was discharged 2 days after.

In patients with LQT3 mutations, the ventricular arrhythmias occur more often during rest and bradycardia is an important triggering factor. The B-blockers may not be beneficial in this group, especially in symptomatic patients ${ }^{2}$. So that, pacemakers have shown to be an effective therapy in preventing sudden death ${ }^{3}$. In addition, dual-chamber pacing permits A-V synchrony,

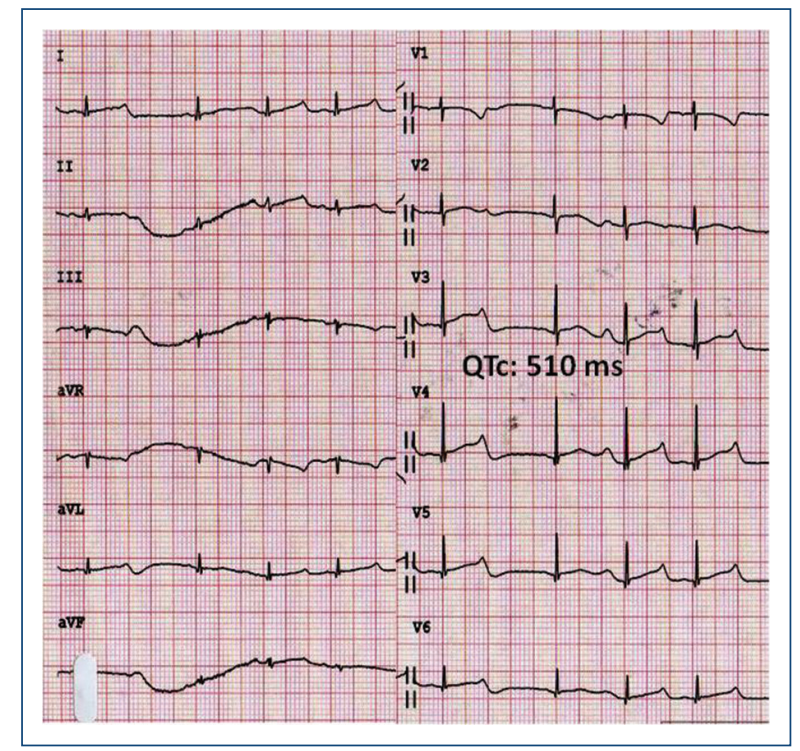

Figure 1. Electrocardiogram with long OT type III with corrected QT (QTc) of $510 \mathrm{~ms}$ and prolonged ST segment.

physiological heart rate, shortening of the QT interval and reduces the risk of $\mathrm{R}$ on $\mathrm{T}$ phenomenon ${ }^{4}$. Once the pacemaker has been implanted, the beta-blocker can started to prevent ventricular arrhythmias. In symptomatic small patients with pause dependent ventricular arrhythmias, the dual-chamber pacemakers are and adequate alternative until they grow up and ICD can be implanted ${ }^{3,4}$.

\section{Correspondence:}

*Leonardo Rivera-Rodríguez

E-mail: rivleonard@gmail.com 2604-7063 / C 2020 Instituto Nacional de Cardiología Ignacio Chávez. Published by Permanyer. This is an open access article under the CC BY-NC-ND license (http://creativecommons.org/licenses/by-nc-nd/4.0/).
Available online: 18-06-2020

Arch Cardiol Mex (Eng). 2021;91(1):114-116

www.archivoscardiologia.com 


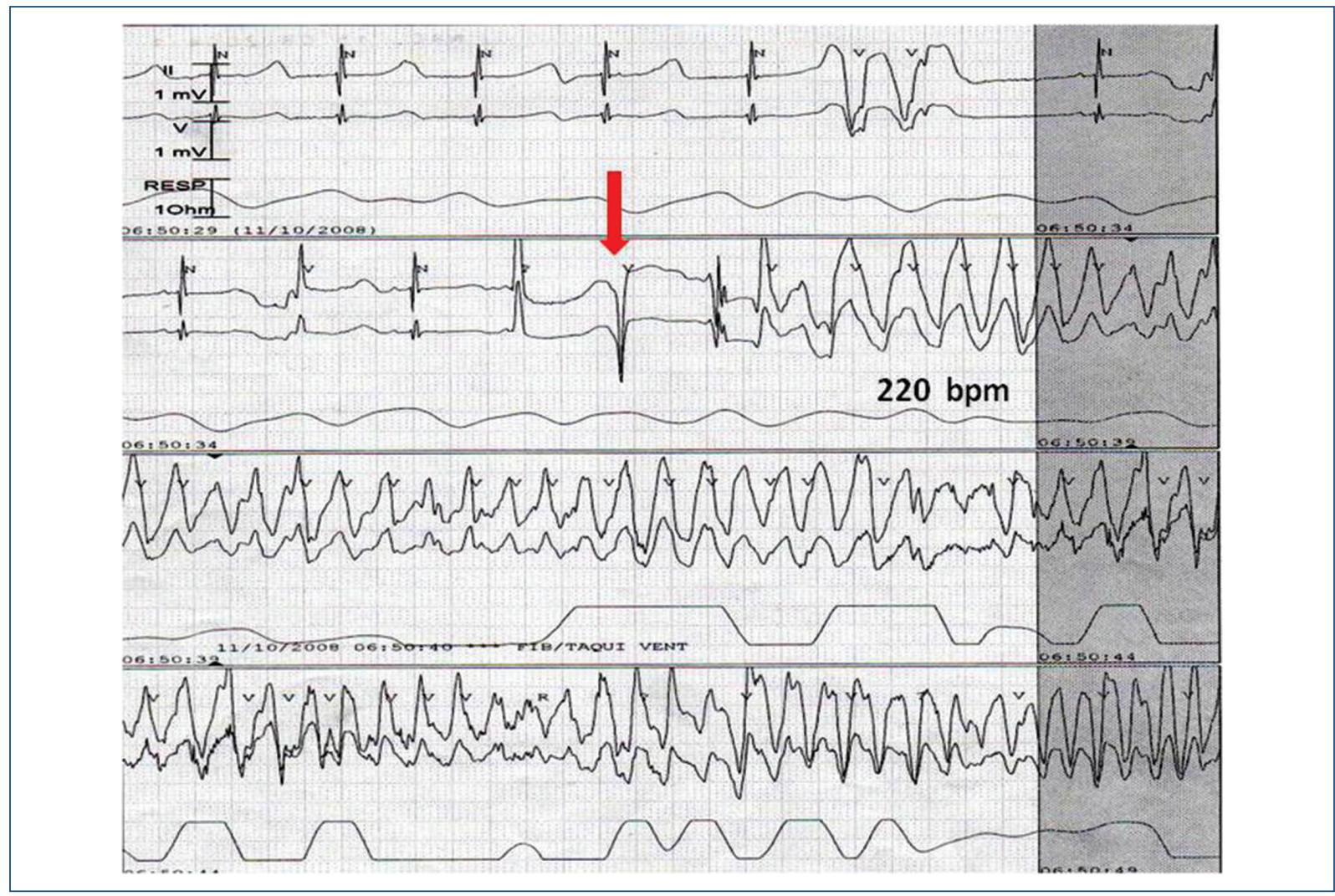

Figure 2. Monitor trace with a polymorphic ventricular tachychardia started with premature ventricular contraction with $\mathrm{R}$ on $\mathrm{T}$ phenomenon (red arrow).

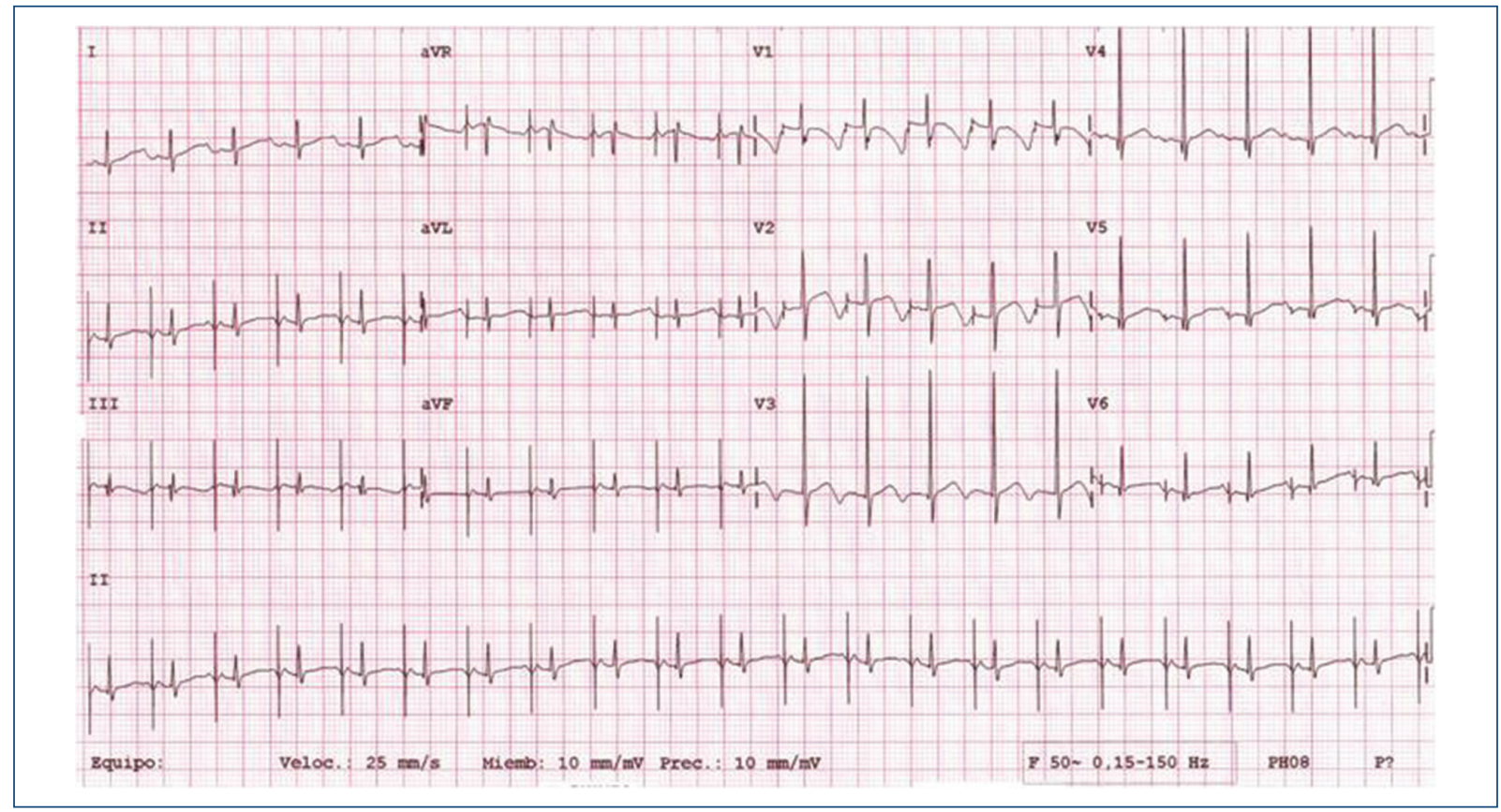

Figure 3. Electrocardiogram with pacemaker bicameral estimulation (DDDR mode), now with AAIR estimulation and shortening of the QT to $460 \mathrm{~ms}$ with a heart rate of $125 \mathrm{bpm}$. 


\section{Funding}

None.

\section{Conflicts of interest}

None.

\section{Ethical disclosures}

Protection of human and animal subjects. The authors declare that no experiments were performed on humans or animals for this study.

Confidentiality of data. The authors declare that they have followed the protocols of their work center on the publication of patient data.
Right to privacy and informed consent. The authors have obtained the written informed consent of the patients or subjects mentioned in the article. The corresponding author is in possession of this document.

\section{References}

1. Lewandoski M, Syska P, Kowalik I, Maciąg A, Sterliński M, Ateńska-Pawłowska J, et al. Fifteen years' experience of implantable cardioverter defibrillator in children and young adults: mortality and complications study. Pediatr Int. 2018;60:923-30.

2. Pérez-Riera AR, Barbosa-Barros R, Raimundo RD, da Costa de Rezende Barbosa MP, Sorpreso IC, de Abreu LC, et al. The congenital long QT syndrome Type 3: an update. Indian Pacing Electrophysiol J. 2018;18:25-35.

3. Wilde AA, Moss AJ, Kaufman ES, Shimizu W, Peterson DR, Benhorin J, et al. Clinical aspects of Type 3 long-QT syndrome: an international multicenter study. Circulation. 2016;134:872-82.

4. Aziz PF, Tanel RE, Zelster IJ, Pass RH, Wieand TS, Vetter VL, et al. Congenital long QT syndrome and 2:1 atrioventricular block: an optimistic outcome in the current era. Heart Rhythm. 2010;7:781-5. 